\title{
The Influence of Location, Tree Age and Forest Habitat Type on Basic Fuel Properties of the Wood of the Silver Birch (Betula pendula Roth.) in Poland
}

\author{
Hubert Lachowicz ${ }^{1} \cdot$ Magdalena Sajdak $^{2} \cdot$ Piotr Paschalis-Jakubowicz ${ }^{1} \cdot$ Wojciech Cichy ${ }^{2} \cdot$ Rafał Wojtan $^{3}$. \\ Magdalena Witczak²
}

Published online: 20 June 2018

(C) The Author(s) 2018

\begin{abstract}
The most extensive study to be carried out in Poland, and one of only a few worldwide, regarding the influence of location, tree age and forest habitat type on the basic fuel properties of silver birch (Betula pendula Roth.) wood was conducted in 12 Forestry Districts of the Polish State Forests. The field study included trees in three age groups of approximately 30, 50 and 70 years. The research was carried out in a fresh broadleaved forest (FBF) habitat type, where in Poland silver birch stands predominate in respect of coverage area and merchantable volume. Additionally, for five selected Forestry Districts, a comparative study was conducted in a fresh mixed broadleaved forest (FMBF), the second most important habitat of this tree species. A total of 306 test trees were examined. For every sample, calorific value and contents of ash, carbon, hydrogen, nitrogen, sulphur and chlorine were determined. The results indicated a statistically significant influence of location on the calorific value $(p=0.0001)$ and on the contents of ash $(p<0.0001)$, carbon $(p<$ $0.0001)$, hydrogen $(p<0.0001)$, nitrogen $(p<0.0001)$ and chlorine $(p<0.0001)$ in the analysed wood. Moreover, statistically significant differences were observed between values of ash content $(p=0.046)$ and of calorific value $(p=0.0026)$ depending on the forest habitat type. Tree age was found to have no significant influence on the calorific value of silver birch wood.
\end{abstract}

Keywords Silver birch $\cdot$ Calorific value $\cdot$ Elemental composition · Forest habitat type $\cdot$ Tree age

\section{Introduction}

Knowledge of certain physical and chemical parameters of wood is of key importance in determining its possible uses. When wood is to be used as a source of energy, the most important parameters include calorific value, moisture content, ash content and elemental composition [1-3]. These parameters, as well as their influence on the combustion process and on the suitability of wood for bioenergy production, are

Magdalena Sajdak

m_sajdak@itd.poznan.pl

Hubert Lachowicz

hubert.lachowicz@wl.sggw.pl

Piotr Paschalis-Jakubowicz

piotr.paschalis@wl.sggw.pl

Wojciech Cichy

w_cichy@itd.poznan.pl

Rafał Wojtan

rwojtan@wl.sggw.pl well-known and documented in the world literature [2, 4-6]. However, only a few studies have so far considered the variation of these main fuel properties of wood under the influence of external factors such as location and forest habitat type or under the influence of tree age.

In Poland, the first large-scale studies of this type were pilot studies of birch stands conducted in the years 2003-2007 in the north-eastern part of the country. These pilot studies focused on variation in physical and mechanical properties and

Magdalena Witczak

m_witczak@itd.poznan.pl

1 Department of Forest Utilization, Warsaw University of Life Sciences (SGGW), Nowoursynowska Str 159, 02-776 Warsaw, Poland

2 Wood Technology Institute, Winiarska Str 1, 60-654 Poznan, Poland

3 Laboratory of Dendrometry and Forest Productivity, Warsaw University of Life Sciences (SGGW), Nowoursynowska Str 159, 02-776 Warsaw, Poland 
served as preparation for the current very broad studies of the fuel properties of the wood of silver birch (Betula pendula Roth.), an economically important forest-forming tree species which presently accounts for $7.3 \%$ [7] of the total area of Polish forests. The importance of research on this species results from the continuous increase in its area share among the broadleaved tree species found in Polish forests, as well as changes in the natural range of the main forest-forming species. Another factor is the quantity of timber delivered and sold. At present, birch is the leader among broadleaved tree species, ahead of beech and oak. According to the State Forests reports, the sourcing and trading of birch timber is at a level of approximately 3 million cubic metres per annum [8].

The results of the pilot studies of silver birch wood showed the significant influence of the selected external factors on most of the analysed structural, physical and mechanical properties of the trees [9-11]. The FBF habitat type was found to have a significant influence on average values of, among others, the elasticity coefficient, rigidity coefficient, Runkel's ratio, wood density and compressive strength along fibres. However, the forest habitat type was observed to have no significant influence on average values of, for example, the slenderness and wood compactness coefficients, or resistance to stretching along fibres, lengthwise compression or static bending [12, 13].

These pilot studies, however, lacked analysis of the influence of location, age and forest habitat type on the main fuel parameters of silver birch wood. Only a few reports on the influence of tree age on fuel properties can be found in the literature; among others, for the species Propolis africana and Balanites aegypyiaca [14] and for varieties of eucalyptus [15-18]. These studies report higher calorific values for the wood of older trees, higher ash contents in the wood of younger trees and a lack of influence of age on the carbon content [17]. We are not aware of any previous studies concerning the influence of forest habitat type, location and age on the parameters of silver birch wood significant for its use as an energy source. The study reported here serves to fill that gap.

The main aim of this study was to analyse variation in the calorific value, ash content and elemental composition of silver birch wood from main resource bases, distributed throughout Poland, depending on the geographical location of the test plots, on the age of the trees and on the forest habitat type. The detailed analyses of selected fuel properties of silver birch serve to assess the quality of the wood in terms of its suitability for bioenergy production.

\section{Materials and Methods}

\section{Study Site}

The research was conducted in two forest habitat types where, in Poland, silver birch stands predominate in respect of coverage area and merchantable volume. Forest habitat type is a fundamental unit in the classification system of forest habitats, grouping together forest areas with similar habitat conditions resulting from the fertility and the humidity of the soil, similitude of climate and landform features and geological structure. Areas belonging to the same forest habitat type are found to be similar in terms of production capacity and silviculture [19]. This study included the FBF and the FMBF habitat types. The first-FBF-is a lowland habitat type and includes very fertile and fresh forest habitats. It is found on sites with brown soil, mainly leach, sometimes acidic or proper brown soil, proper lessive, with mull type humus or typical mull. The second-FMBF-is a lowland habitat type that includes fresh habitats of average fertility. It is found on brown leach, podzol or acidic soils, proper fawn soils, spodic, sometimes on podzoluvisols, proper podzol or rusty soils mostly with typical humus. The field research was conducted in 12 Forestry Districts (FDs) with FBF as the dominant forest habitat, and for five of the FDs comparative studies were also conducted on the FMBF habitat type. The studied FDs were the following: Płońsk (FBF), Sokołów (FBF), Biała Podlaska (FBF), Płaska (FBF), Giżycko (FBF and FMBF), Górowo Iławeckie (FBF), Elblag (FBF), Mircze (FBF), Bobolice (FBF and FMBF), Łobez (FBF and FMBF), Lipinki (FBF and FMBF) and Rudziniec (FBF and FMBF). The locations of the FDs where test plots were established are shown on Fig. 1.

\section{Field Sampling, Sample Selection and Preparation}

Breast height diameters (BHD) were measured for all trees growing on the test plots for which those diameters exceeded $7 \mathrm{~cm} \mathrm{[20].} \mathrm{The} \mathrm{sample} \mathrm{trees} \mathrm{on} \mathrm{the} \mathrm{test} \mathrm{plots} \mathrm{were}$ chosen using Hartig's method, based on the mean BHD area with three thickness classes [21]: class 1, containing the thinnest trees; class 2, with trees of medium thickness; and class 3, with the thickest trees. From each thickness class, two trees were selected and felled, giving a total of six trees from each sample plot. In total, sample materials were collected from 306 trees. Two or three 50-cm-long trunk sections were cut out (below the 1.3-m height point and $50-100 \mathrm{~cm}$ above it) and were then split open and marked appropriately. Wood samples (without bark and knots) characterised by a homogeneous structure (without technical defects) were collected for testing. After seasoning, when the wood moisture content reached a level of approximately $15 \%$, the samples were taken for chemical analysis. Afterwards, sample material was ground in a knife mill and sieved to the desired particle size. Analysis of fuel properties was carried out on 51 samples of birch wood obtained from selected locations in Poland from trees in three age categories: approximately 30,50 and 70 years old. For each of the 51 samples, the mean value from two 
Fig. 1 Geographical distribution of the National Forestry Districts where the test plots were located or three replicate determinations was taken for further calculations. The analyses were therefore based on between 102 and 147 determinations.

\section{Determination of Moisture Content (\%), Elemental Composition (\%), Ash Content (\%) and Calorific Value (MJ/kg)}

The ash content in the samples was determined according to [22]. Samples were roasted at a temperature of (550 \pm 10) ${ }^{\circ} \mathrm{C}$. Moisture content was determined using a drying and weighing method at a temperature of $(105 \pm 2){ }^{\circ} \mathrm{C}$ according to [23]. Elemental analysis of the content of carbon $(\mathrm{C})$, hydrogen $(\mathrm{H})$, nitrogen $(\mathrm{N})$ and sulphur $(\mathrm{S})$ was performed using the procedures described in $[24,25]$. The heat of combustion was determined according to [26]. After being ground to a particle size not greater than $0.2 \mathrm{~mm}$, samples were burnt in a calorimetric bomb filled with oxygen under a pressure of $3.0 \pm 0.2 \mathrm{MPa}$. The heat of combustion was calculated using the Regnault-Pfaundler method, taking into account corrected temperature increases and the thermal capacity of the calorimeter. Calculations of the calorific value were performed according to [26]. The chlorine content was determined according to [25]. The determination was carried out with the use of the potentiometric titration method.

\section{Statistical Analysis}

For analysis of the influence of test plot location and tree age on the values of the selected characteristics, the KruskalWallis test was employed. This is a nonparametric alternative to analysis of variance. The reason for the choice of this analytical method was the fact that the data did not meet the assumption of unity of variance (Levene's test: $p<0.001$ ) and that some of the analysed groups did not follow a normal distribution. Following the identification of statistically significant differences between the analysed categories, a multiple range rank test was carried out to find groups with similar values for the analysed characteristics. On the data representing five FDs (Giżycko, Bobolice, Łobez, Lipinki and Rudziniec), analyses of correlations between values of the studied characteristics and the forest habitat types (FBF and FMBF) were performed. Because of the strong asymmetry of the distribution of the variables, a Mann-Whitney test was applied; this is a nonparametric alternative to the $t$ test $[27$, 28]. The significance level was set at $p<0.05$.

Additionally, to identify locations with similar values as regards the basic elemental composition of the wood, a cluster analysis was carried out. A cluster analysis is a multivariate method which aims to classify a sample of subjects (or objects) based on a set of measured variables into many diverse groups such that similar subjects are placed in the same group. A hierarchical agglomerative method was applied, in which 
Euclidean distances were employed. Grouping of objects was performed using the Ward method, in which the aim is to obtain the smallest variance of the distance within a cluster.

\section{Results}

\section{Influence of Location, Tree Age and Forest Habitat Type on the Heat of Combustion and Calorific Value of Wood}

The mean value of heat of combustion for all samples was $19.66 \mathrm{MJ} / \mathrm{kg}$. For all material from the FBF habitat type, it was $19.68 \mathrm{MJ} / \mathrm{kg}$, and for the five locations where the heat of combustion was compared between habitat types, the mean values were $19.68 \mathrm{MJ} / \mathrm{kg}$ for FBF and 19.62 MJ/kg for FMBF. The results indicate that the influence of the location of test plots on values of heat of combustion is statistically significant $(p=0.0004)$, although the observed differences in the value are minor (Fig. 2). The multiple comparisons of the average rank tests demonstrated statistically significant differences between Mircze and Bobolice FMBF, Łobez FMBF and Lipinki FMBF, as well as between Bobolice FMBF and Giżycko FMBF. Statistically significant differences $(p=0.01)$ were also observed in values of the heat of combustion depending on the forest habitat type (Fig. 3). On the other hand, a comparison of values of heat of combustion among different tree ages demonstrated the lack of statistically significant differences $(p=0.08)$.

The mean calorific value for all samples was $18.27 \mathrm{MJ} / \mathrm{kg}$. For all material from the FBF habitat type, it was $18.29 \mathrm{MJ} / \mathrm{kg}$, and for the five locations where the heat of combustion was compared between habitat types, the mean values were $18.28 \mathrm{MJ} / \mathrm{kg}$ on FBF and $18.20 \mathrm{MJ} / \mathrm{kg}$ on FMBF. The location of the sample plots was shown to have a statistically significant influence $(p<0.0001)$ on the calorific value (Fig. 4$)$. The multiple comparisons of the average rank tests demonstrated statistically significant differences between data from Mircze and Bobolice FMBF, Lobez FMBF and Lipinki FMBF. Statistically significant differences $(p=0.0026)$ were also observed in calorific values depending on the forest habitat type (Fig. 5). Tree age was found to have no significant influence on the calorific value $(p=0.92)$.

\section{Influence of Location, Tree Age and Forest Habitat Type on Ash Content}

The mean ash content for all samples was $0.24 \%$. For material from the FBF habitat type, it was $0.25 \%$. In the five Forestry Districts where habitat types were compared, the value for FBF was $0.26 \%$, slightly higher than the value of $0.23 \%$ calculated for FMBF. Averages of ash content increased along with tree age, but differed only slightly. The location of the sample plots was shown to have a statistically significant influence $(p<0.0001)$ on the ash content (Fig. 6). The multiple comparisons of the average rank tests demonstrated statistically significant differences between data from Łobez FBF and from Giżycko FBF and Bobolice FBF, FMBF. A comparison of ash content among different tree ages demonstrated a lack of statistically significant differences $(p=0.70)$. Statistically significant differences $(p=0.046)$ were recorded between values of the analysed characteristic depending on forest habitat type (Fig. 7).

\section{Influence of Location, Tree Age and Forest Habitat Type on Elemental Composition}

\section{Carbon Content}

The mean carbon content in the silver birch wood for all samples was $49.39 \%$. For all material from the FBF habitat type, it was $49.18 \%$. For the five locations where habitat types were compared, the value for FBF was $49.63 \%$, slightly lower than the value of $49.91 \%$ determined for FMBF. Carbon content was found to decrease with increasing tree age, averaging $49.96 \%$ in the wood of 30 -year-old trees, $49.13 \%$ in 50 year-old trees and $49.08 \%$ in 70 -year-old trees. The test plot location was shown to have a statistically significant influence $(p<0.0001)$ on the carbon content (Fig. 8). The multiple comparisons of the average rank test demonstrated statistically significant differences between the data from Lipinki FBF, FMBF and the data obtained from Płońsk, Biała Podlaska, Płaska, Giżycko FBF and Elblag. A comparison of carbon content among trees of different ages also showed statistically significant differences $(p=0.0013)$ (Fig. 9). The highest values were recorded in the youngest forest stands (30 years), where the differences in carbon content from the remaining tree ages were statistically significant. This fact was confirmed by multiple comparisons of the average rank test. No statistically significant differences were found between the results obtained from samples originating from 50- and 70-year-old trees. Also, no statistically significant differences were noted $(p=0.33)$ between values of the analysed characteristic depending on forest habitat type.

\section{Hydrogen Content}

The mean hydrogen content for all samples was $6.39 \%$. For all material from the FBF habitat type, it was $6.35 \%$. In the five locations where habitat types were compared, the values were $6.40 \%$ for FBF and $6.50 \%$ for FMBF. The highest mean value of hydrogen content was recorded for 30-year-old trees (6.55\%); the value was lower for 50-year-old trees $(6.33 \%)$ and lowest for 70 -year-old trees $(6.30 \%)$. The test plot location was shown to have a statistically significant influence ( $p$ $<0.0001$ ) on the hydrogen content (Fig. 10). The multiple 
Fig. 2 Average values of heat of combustion depending on location

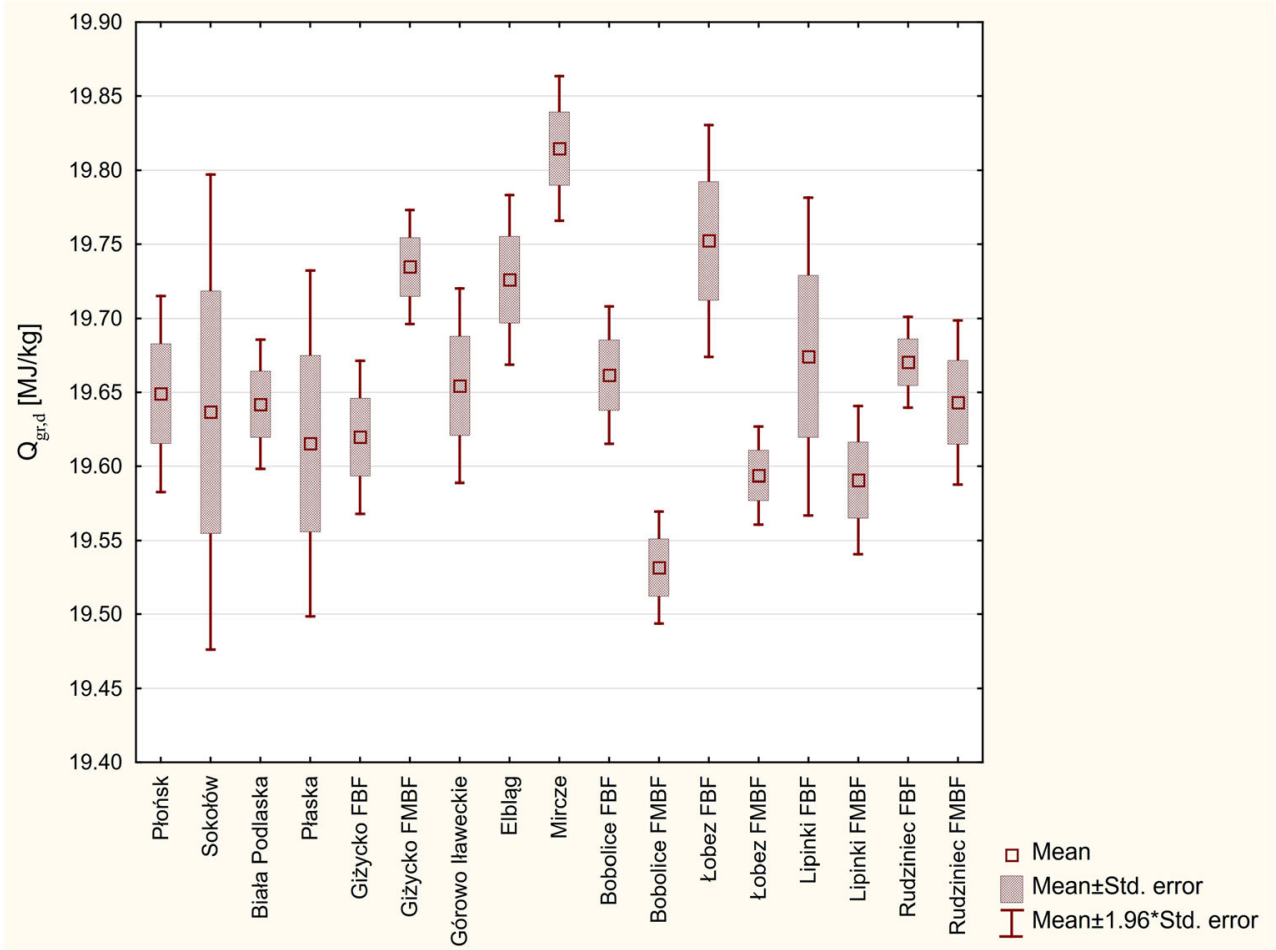

comparisons of the average rank test demonstrated statistically significant differences between the data from Lipinki FBF, FMBF and those obtained from Płońsk and Płaska Forestry Districts. A comparison of hydrogen content among trees of different ages also revealed statistically significant differences $(p=0.0001)$ (Fig. 11). The highest values were recorded in the youngest forest stands (30 years), where the differences in hydrogen content from the remaining tree ages were statistically significant. This fact was confirmed by a multiple comparison of the average rank test. No statistically significant
Fig. 3 Average values of heat of combustion depending on forest habitat type

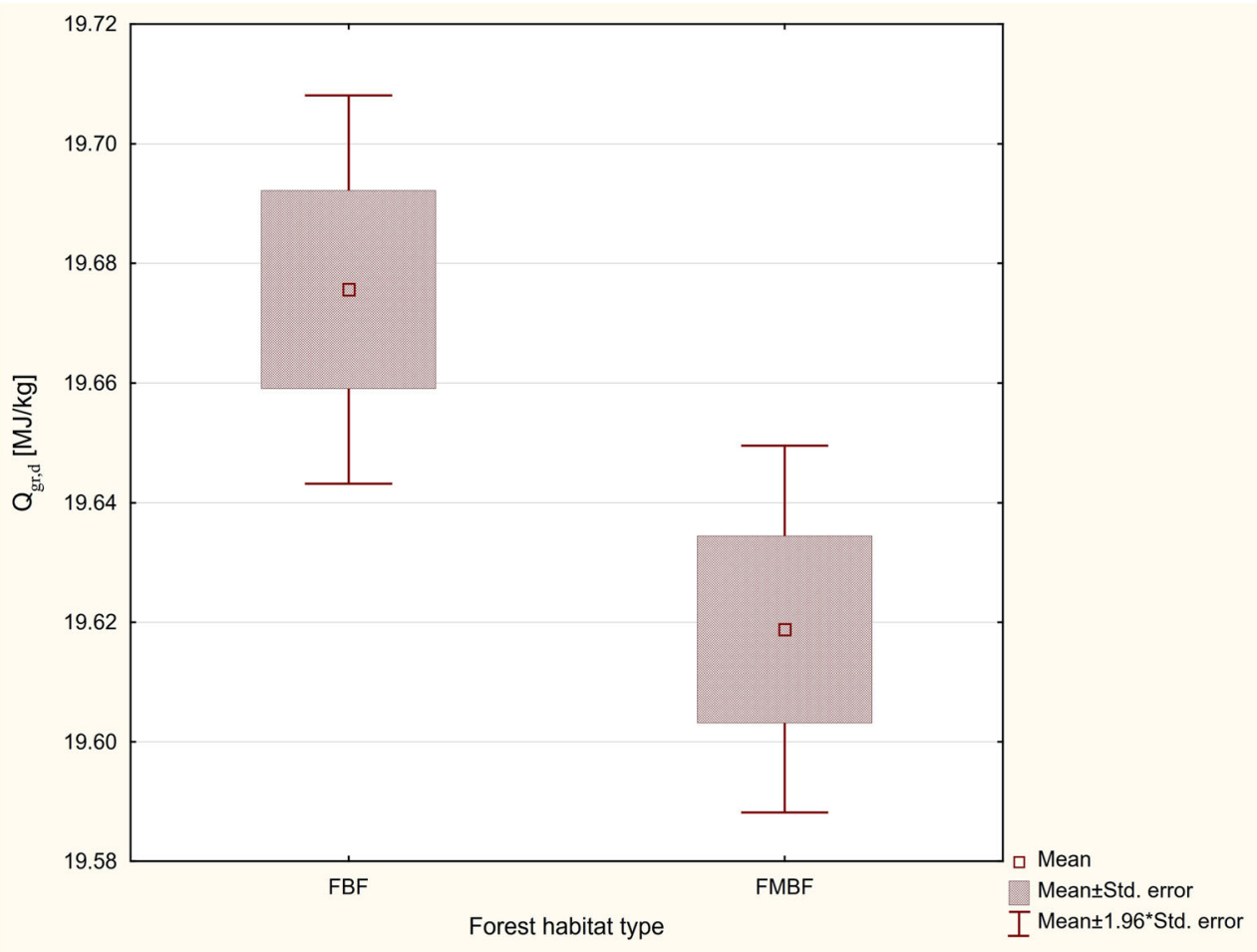


Fig. 4 Average calorific values depending on location

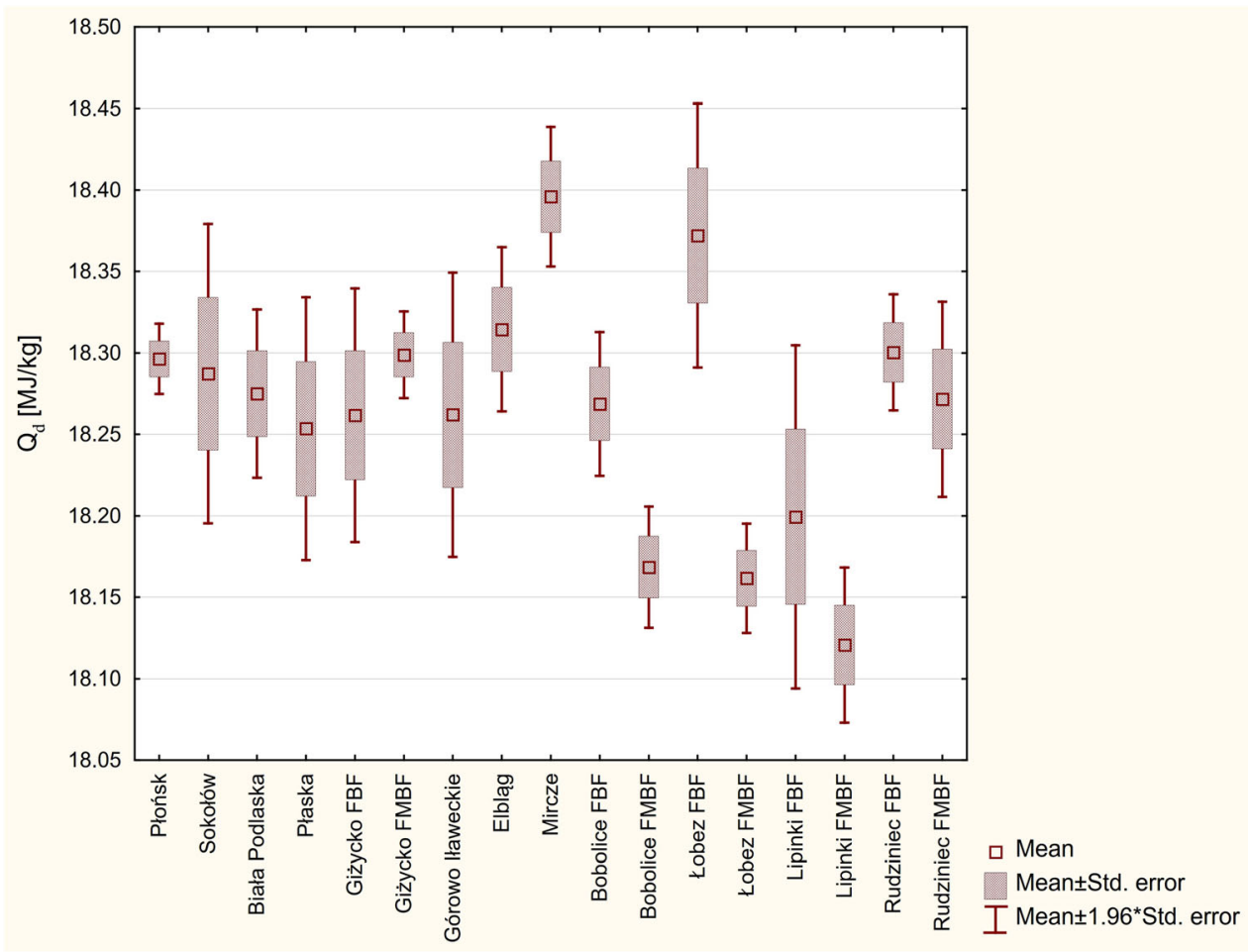

differences were found between the results obtained from samples originating from 50 - and 70 -year-old trees. No statistically significant differences were found $(p=0.06)$ in values of hydrogen content depending on forest habitat type, although the difference between the obtained probability test value and the set significance level $(0.05)$ is very small.

\section{Nitrogen Content}

The mean nitrogen content in silver birch wood for all samples was $0.16 \%$. For all material from the FBF habitat type, it was $0.16 \%$, and for the five locations where habitat types were compared, the value for both FBF and FMBF was $0.17 \%$.
Fig. 5 Average calorific values depending on forest habitat type

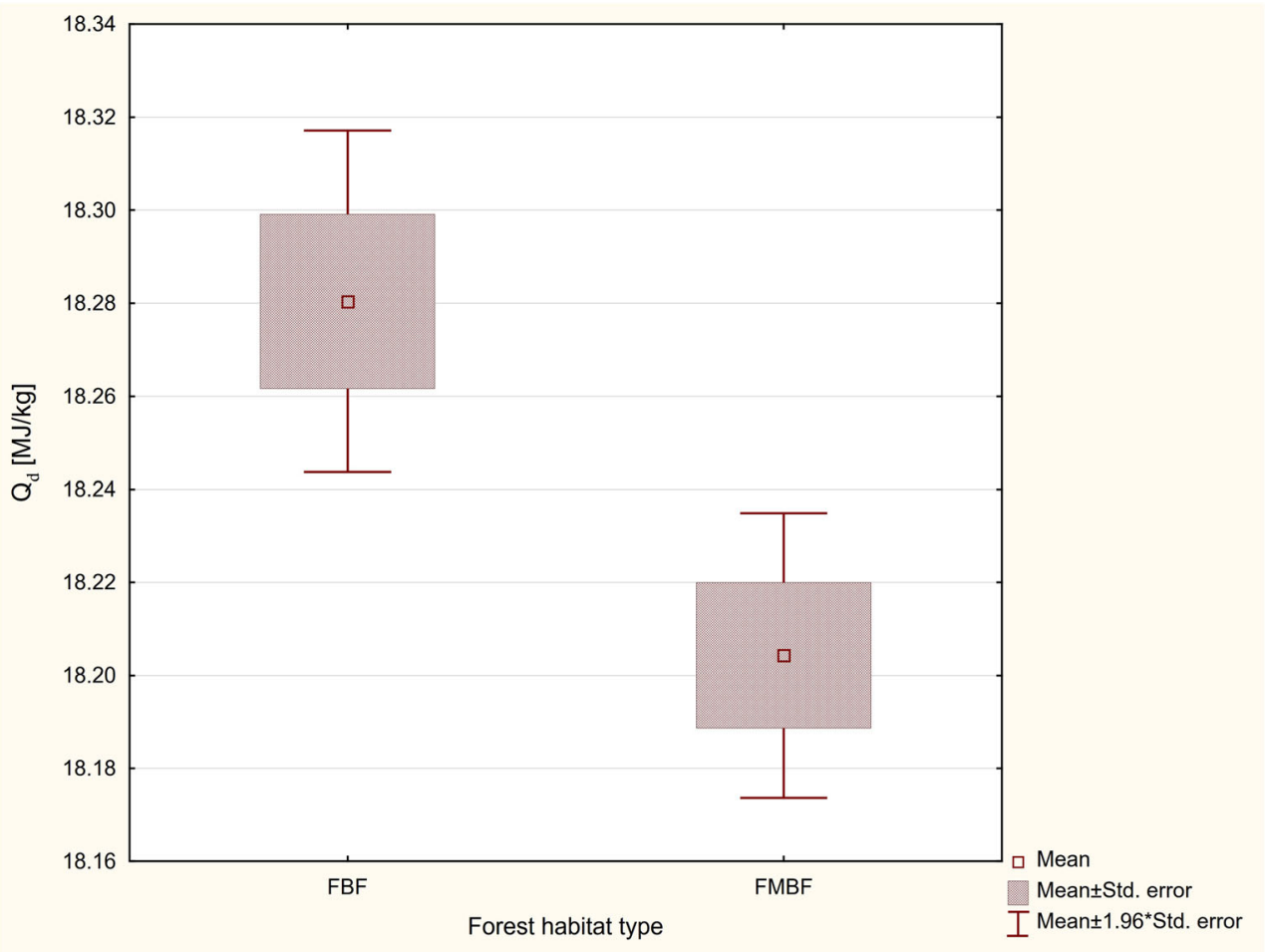


Fig. 6 Average values of ash content depending on location

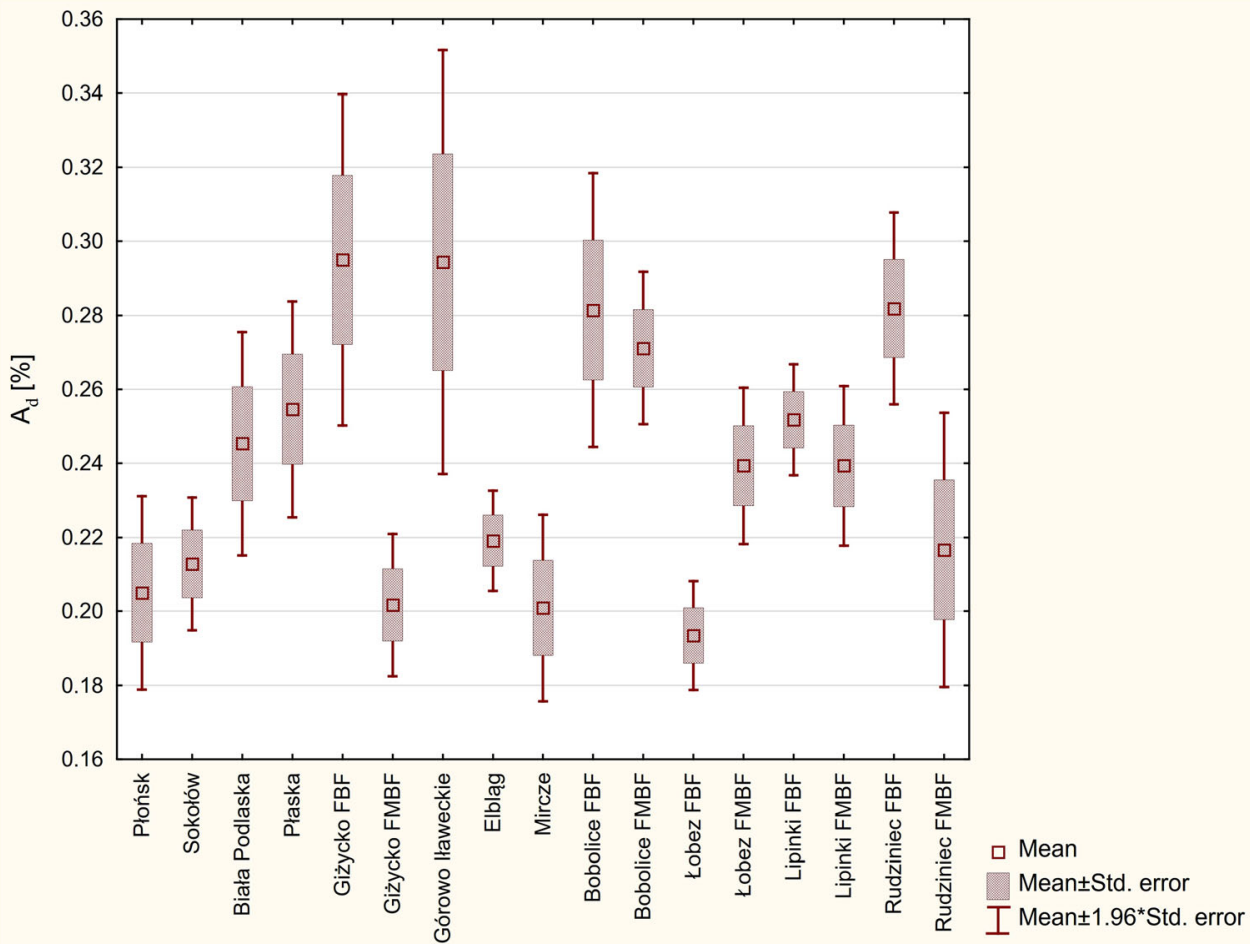

Average nitrogen contents did not differ between tree ages. The test plot location was found to have a statistically significant influence $(p<0.0001)$ on nitrogen content in the birch wood (Fig. 12). The multiple comparisons of the average rank test demonstrated statistically significant differences for data from
Bobolice FBF, FMBF and Rudziniec FBF, FMBF compared with the results from Płońsk, Sokołów, Biała Podlaska, Płaska and Łobez FBF, FMBF. No statistically significant differences were found in the nitrogen content depending on forest habitat type $(p=0.78)$ or depending on tree age $(p=0.22)$.
Fig. 7 Average values of ash content depending on forest habitat type

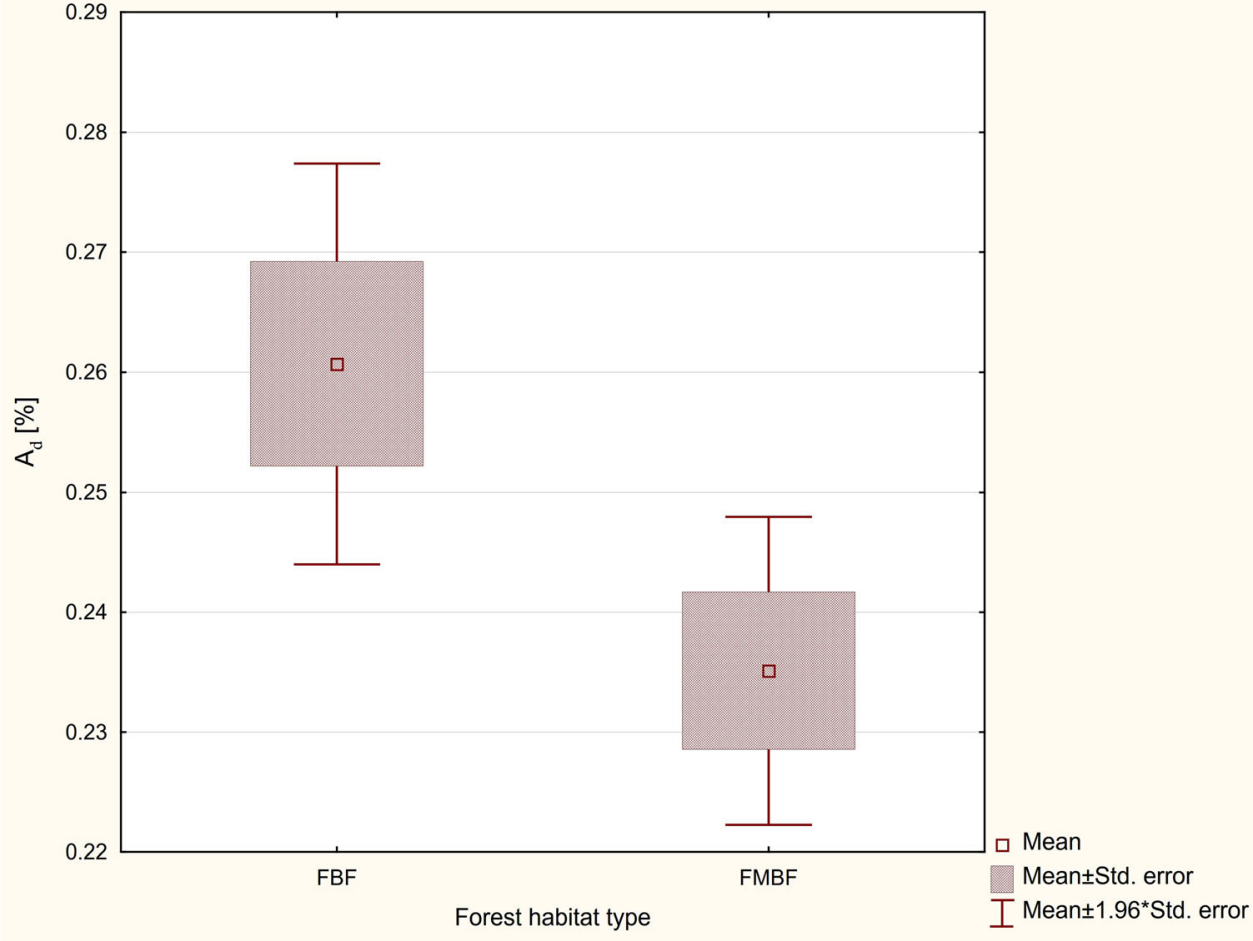


Fig. 8 Average values of carbon content depending on location

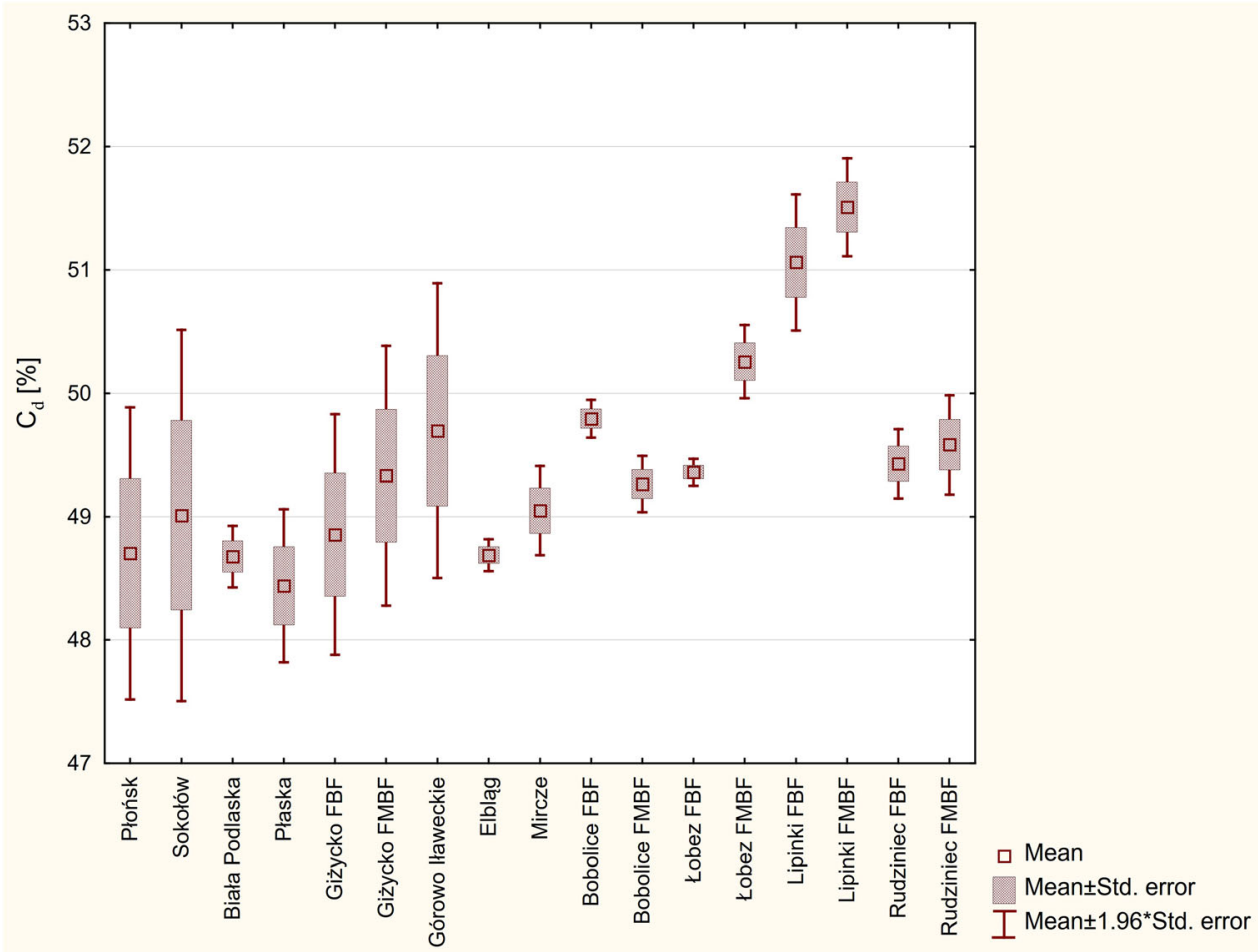

\section{Sulphur Content}

Because in all 51 analysed samples laboratory tests showed the sulphur content to be less than $0.01 \%$, which is below the level of detectability by the methods applied in this study, it should be assumed that the sulphur content in the sampled birch wood is at a minimum level.
Fig. 9 Average values of carbon content depending on tree age

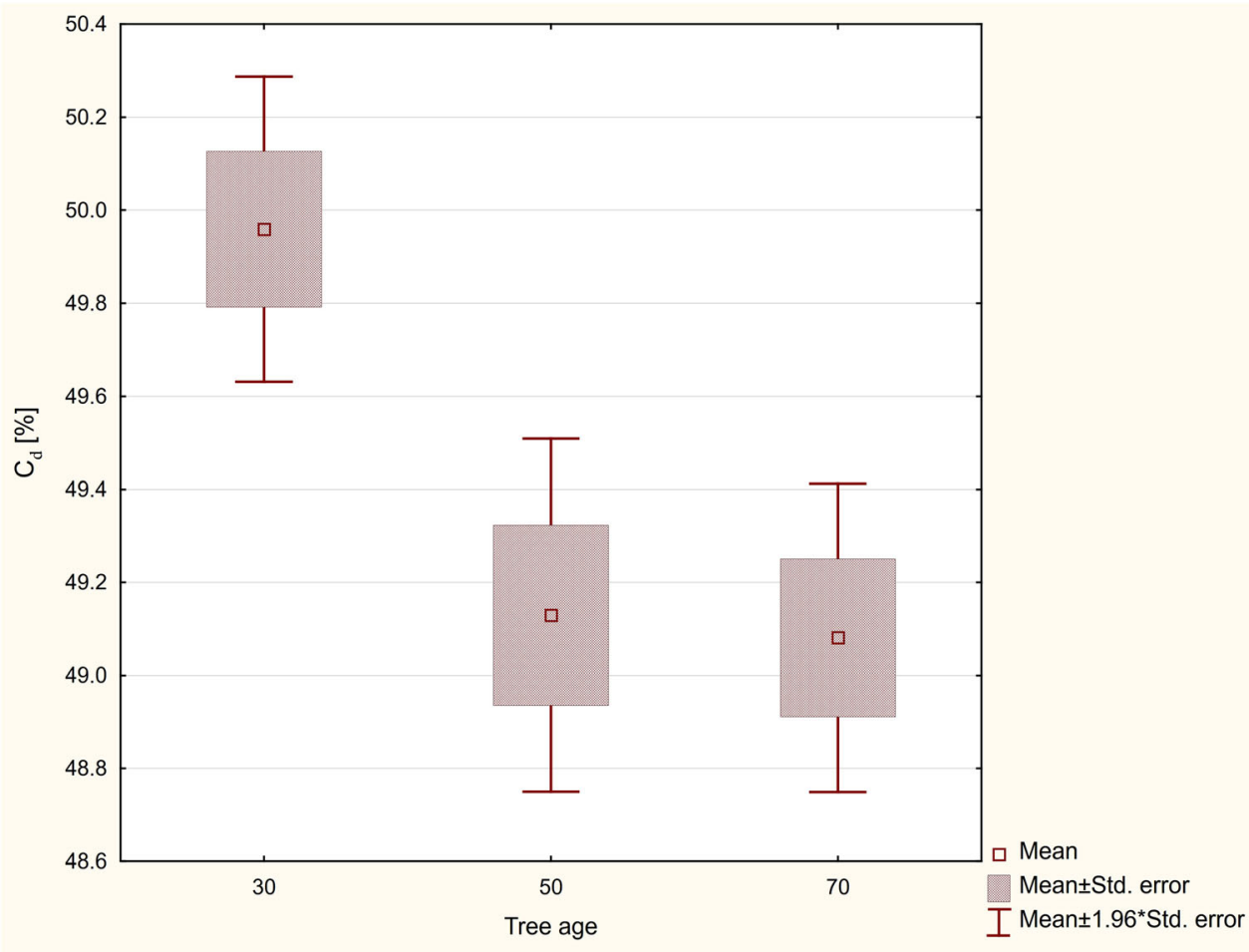


Fig. 10 Average values of hydrogen content depending on location

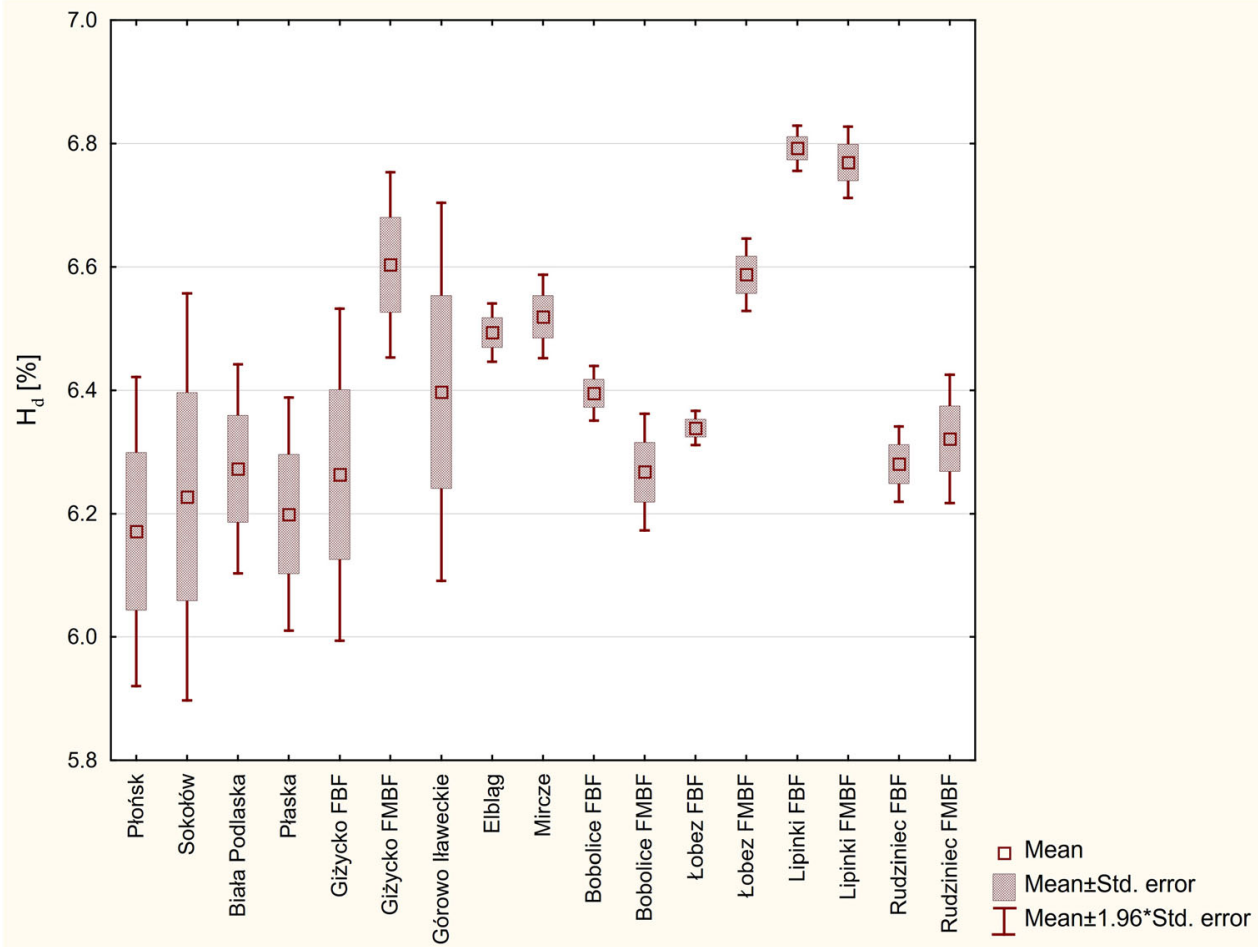

\section{Chlorine Content}

The mean chlorine content for all samples and for all material from the FBF habitat type was $0.0064 \%$. For the five locations where habitat types were compared, the respective values were almost identical: $0.0062 \%$ for FBF and $0.0063 \%$ for FMBF. The average content of chlorine also differed only slightly depending on tree age. The test plot location was found to have a significant influence $(p<0.0001)$ on the chlorine content in birch wood (Fig. 13). Statistically significant
Fig. 11 Average values of hydrogen content depending on tree age

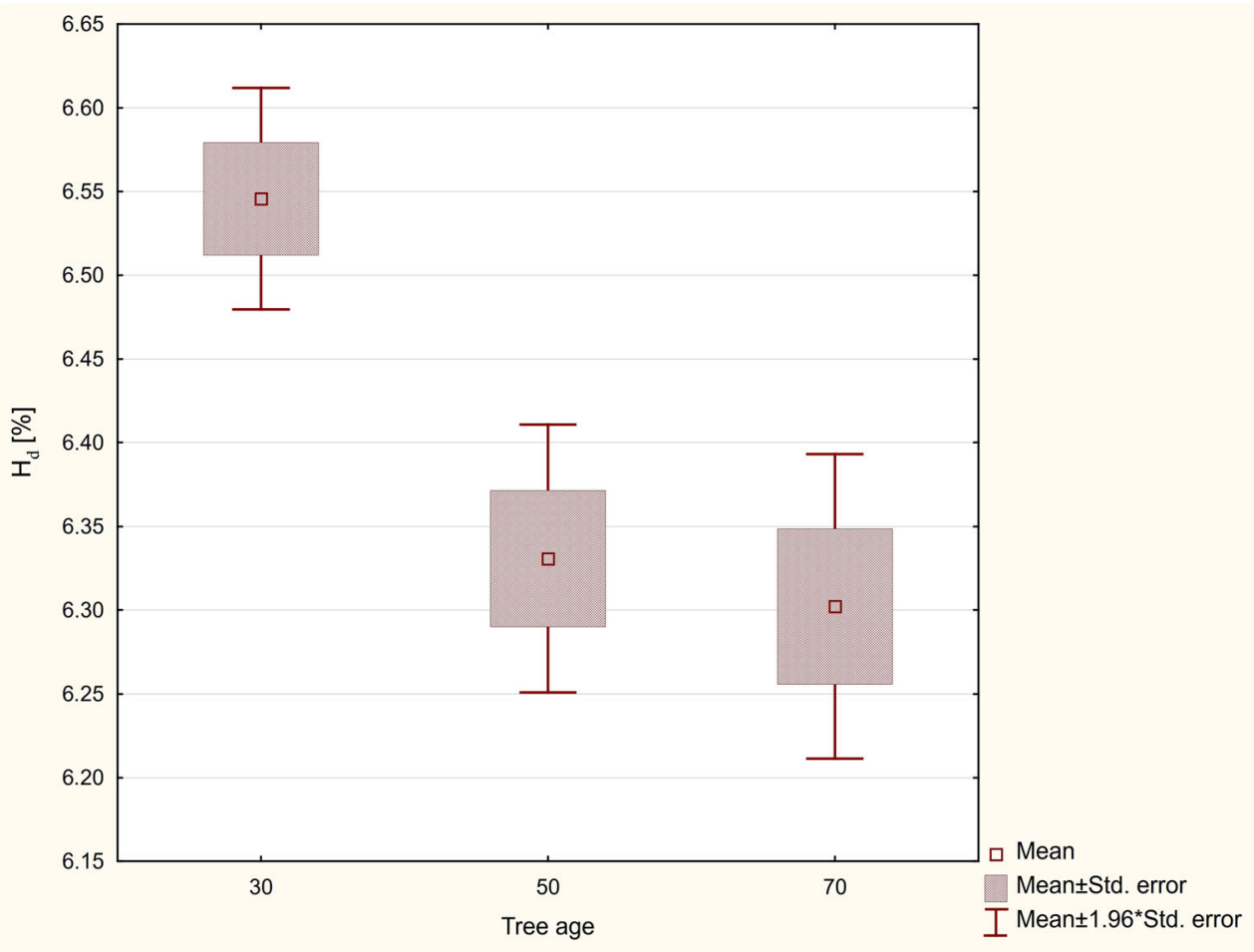


Fig. 12 Average values of nitrogen content depending on location

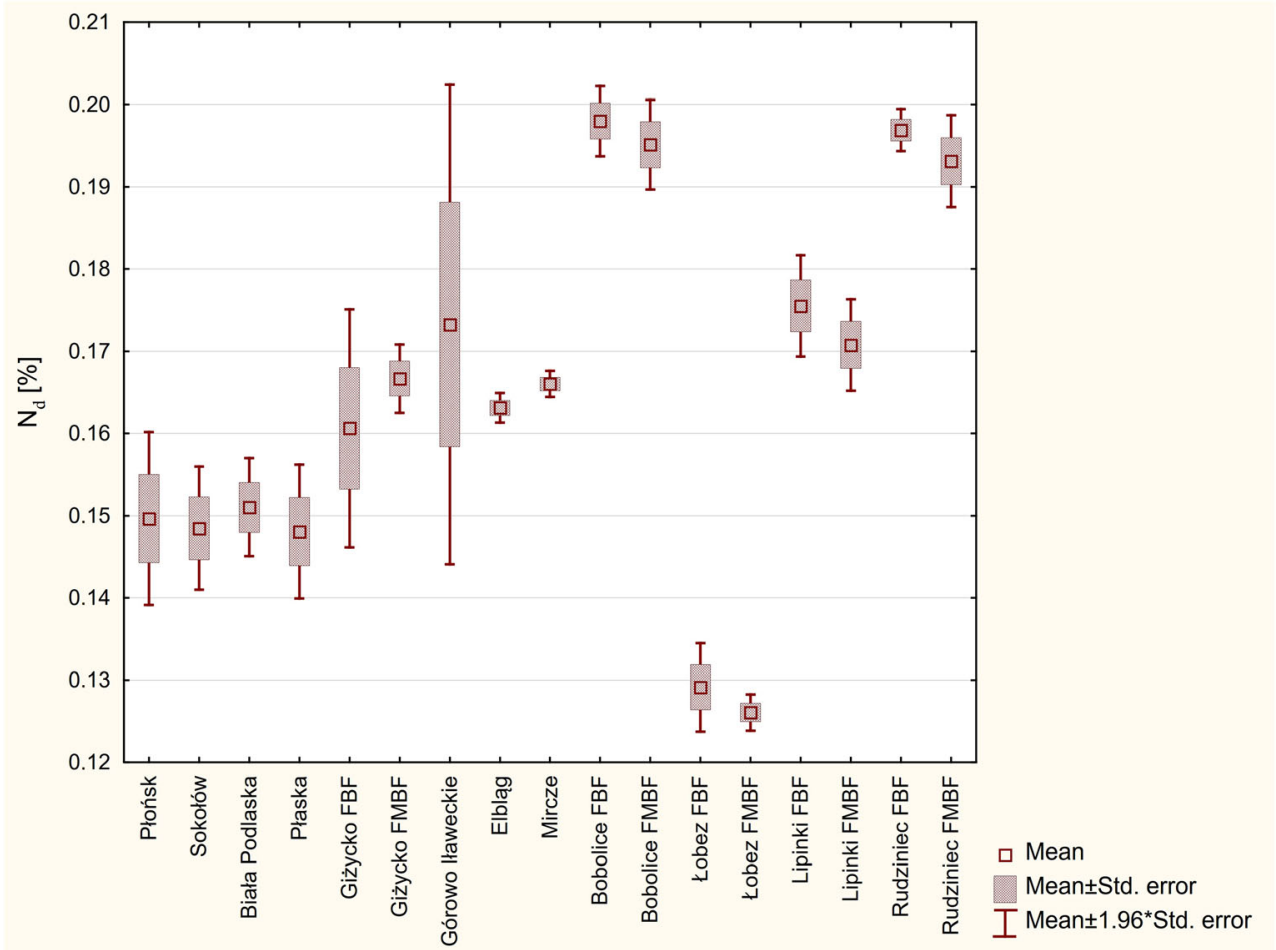

differences were noted between the results from Elblag and those obtained from Bobolice FBF, FMBF and Rudziniec FMBF. No statistically significant differences were noted between the values of the analysed characteristic depending on forest habitat type $(p=0.9641)$ or tree age $(p=0.5483)$.
Cluster analysis, based on values of the parameters of the basic elemental structure of birch wood (percentage of ash, carbon, hydrogen and nitrogen), produced a grouping of the sample plots into three main clusters (Fig. 14). Samples from Lipinki showed the greatest differences in comparison with
Fig. 13 Average values of chlorine content depending on location

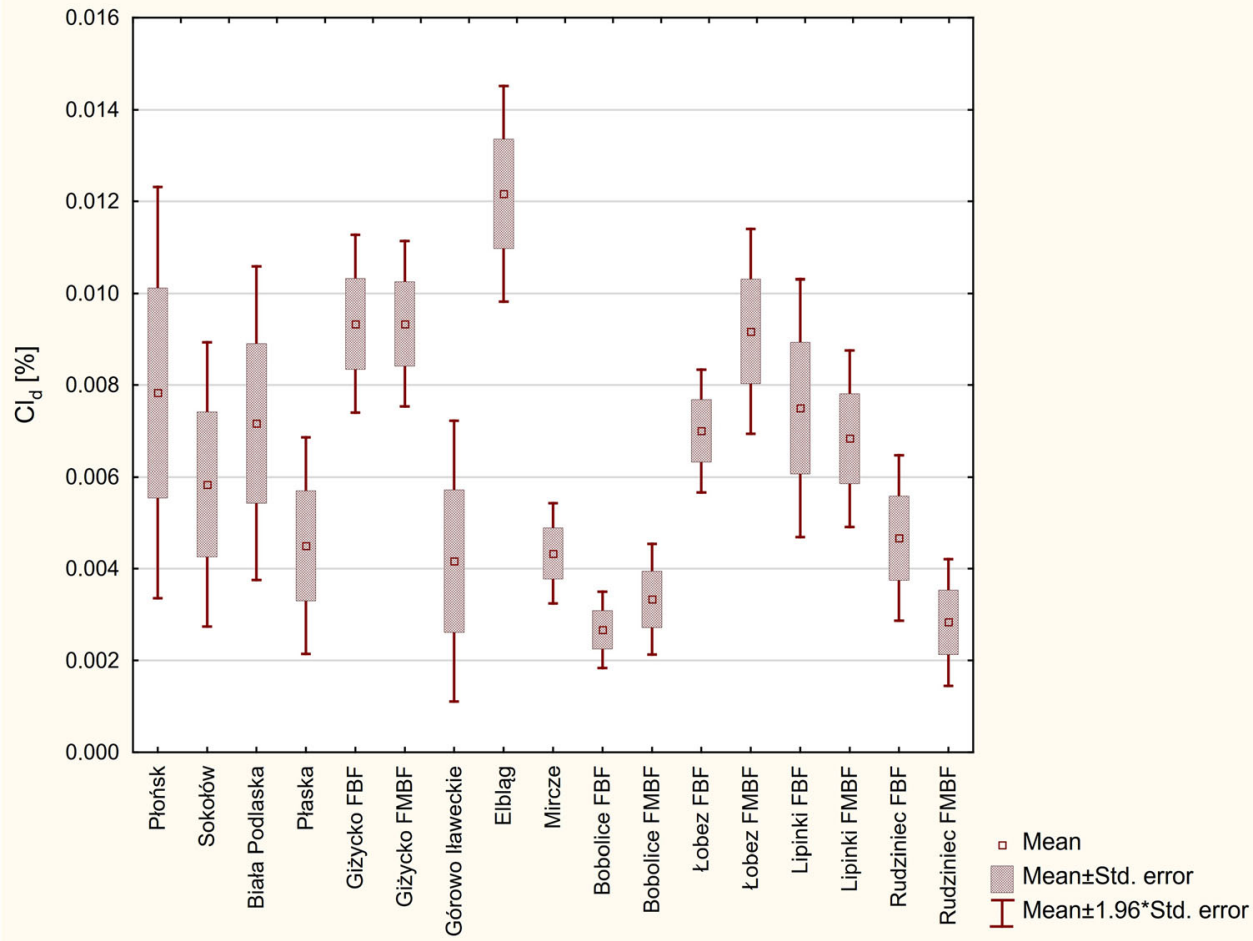


Fig. 14 Result of clustering of sample plots based on values of parameters of the basic elemental structure of birch wood

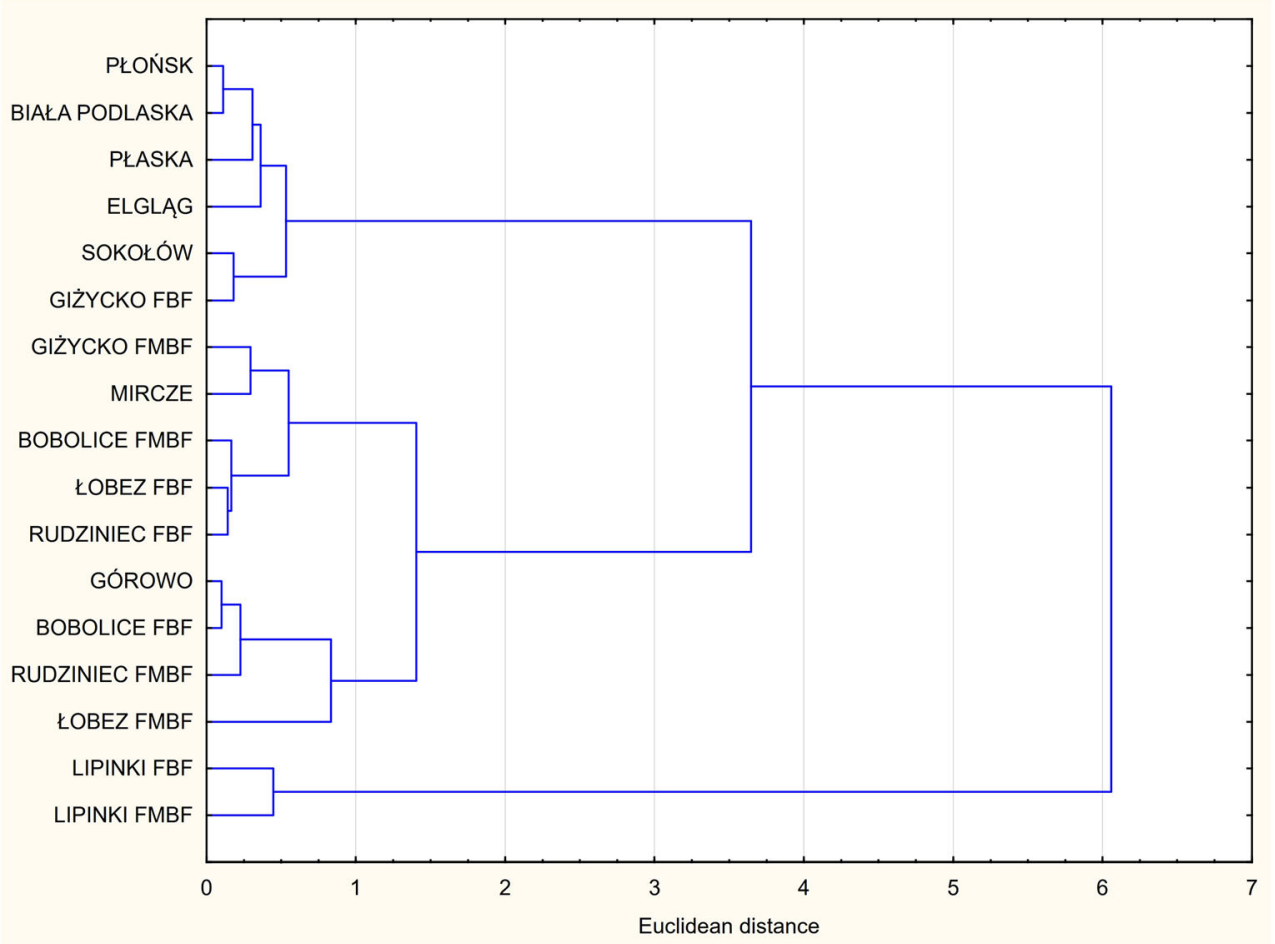

samples from all other locations. Locations in central and north-eastern parts of Poland form a separate cluster. The remaining locations form a group with a very extensive geographical range.

\section{Discussion}

In the literature published in recent years referring to the fuel properties of tree biomass [29, 30], little information is given on the content of structural elements in birch wood. Publications most often refer to wood (wood chip) originating from coniferous or broadleaved trees. Information concerning the elemental composition of birch wood can be obtained from earlier publications. Galewski and Korzeniowski [31] provide the following values from an elemental analysis of silver birch wood: $48.88 \% \mathrm{C}, 6.06 \% \mathrm{H}, 45.26 \% \mathrm{~N}$ and $\mathrm{O}$, $0.29 \%$ ash. According to [32], the elemental composition of birch wood is $48.6 \% \mathrm{C}, 6.4 \% \mathrm{H}$ and $45.0 \% \mathrm{O}$. The latter study states that the elemental composition of the wood depends on the age of the tree and the part from which the samples were obtained and supports this with data according to Lange: $50.61 \% \mathrm{C}, 6.23 \% \mathrm{H}$ and $1.12 \% \mathrm{~N}$ in the trunk of birch trees and $51.93 \% \mathrm{C}, 6.31 \% \mathrm{H}$ and $1.07 \% \mathrm{~N}$ in the branches. However, the study does not specify from which birch species these data were obtained, nor does it suggest reasons for the influence of age. The same author notes that the nitrogen content values are elevated, and for different species in later studies, they range between 0.09 and $0.2 \%$. Progress in instrumental analysis has allowed us to verify most of these data with the use of contemporary measurement techniques. In this respect, our work constitutes a milestone, although the data presented refer to only one species.

In our study, the average value of heat of combustion was $19.66 \mathrm{MJ} / \mathrm{kg}$, but significant differences were found between birch wood originating from various locations and forest habitat types. It should be emphasised, however, that these differences were small, amounting to a maximum of $520 \mathrm{~kJ} / \mathrm{kg}$ (between Rudziniec FBF and Sokołów FBF) for extreme values and just $280 \mathrm{~kJ} / \mathrm{kg}$ (between Mircze and Bobolice FMBF) for average values. The reasons for the dissimilarities can be found in minor differences in the chemical composition of the wood, particularly in relation to the polysaccharide fraction and lignin. Janežić et al. [33] reported that the higher value of the heat of combustion of lignin, compared with polysaccharides, results from the higher ratio of carbon to hydrogen in that substance. White [34] pointed out the linearly increasing relationship between the content of lignin in combusted wood and the heat of combustion. He found that the content of extractives was an additional factor, increasing the heat of combustion by up to $4 \%$. With respect to the heat of combustion, the calorific value is a relative parameter dependent mainly on the content of non-flammable substances such as ash or water and on the amount of hydrogen, nitrogen and sulphur. According to the published literature [35], the average calorific value for various wood species in dry state is approximately $19 \mathrm{MJ} / \mathrm{kg}$. This value varies to a small extent between species, owing to the different contents of extractives 
(e.g. resin and fatty acids, terpenes) and of non-flammable substances (e.g. ash). The calorific value indicates the actual quantity of heat obtained from the combustion process; therefore, it is a parameter that characterises the technical properties of combustible materials. The moisture content exerts the largest impact on the calorific value. As a result, the difference between values of this parameter for wood in dry state and with considerable moisture content can amount to 5-15 MJ/ $\mathrm{kg}$. Considering the great ease of absorption and loss of moisture in the case of natural (virgin) wood, the observed differences in the calorific value for the dry state $(280-440 \mathrm{~kJ} / \mathrm{kg}$ ) are of no practical significance from a technical point of view.

Regarding ash content, the average for all samples was $0.24 \%$, and the differences in average values were up to $0.09 \%$ (between data from Łobez FBF and those from Bobolice FBF and Rudzieniec FBF), while differences between extreme values were up to $0.24 \%$ (between data from Górowo Iławieckie FBF and those from Mircze and Lobez FBF). In general, the content of ash indicates the presence of mineral elements in the tested sample. In the case of the wood of forest trees, the variable content of mineral elements may be related to the forest habitat type from which samples originate and particularly the type of soil on which the trees grew. According to [36], the ash content in the natural (virgin) wood of two birch species is $0.7 \%$ (Betula alleghaniensis) and $0.3 \%$ (Betula papyrifera). For fuel wood, higher values of this indicator are permissible; this may be associated with the content of secondary pollutants (sand, soil and the like). Such low contents of minerals in the analysed samples of birch wood have minimal influence on the calorific value. Industrial practices allow a much greater ash content in fuel; for example, for the highestgrade wood pellets [37], the acceptable content of ash is $1.5 \%$.

Regarding the content of carbon in samples of silver birch wood, the differences between average values reached $2.61 \%$ (between Płaska and Lipinki FBF), while the differences between extreme values were twice as high, reaching $5.23 \%$ (between Sokołów and Lipinki FMBF). The mean carbon content for all samples (49.39\%) was slightly higher than the figure reported in the literature $(48.88 \%)$ [31]. This parameter has a significant effect on the heat of combustion of organic substances. During the oxidation of carbon to carbon dioxide, energy is released, which is measured to determine the value of the heat of combustion.

Hydrogen can be found in almost all organic compounds. It also has a significant effect on energy parameters-via the synthesis of hydrogen with oxygen, a water molecule is created. This reaction releases energy, which makes a direct contribution to the heat of combustion. In turn, the condensing water draws heat from the reaction, thus lowering the calorific value. Analysis of the data concerning the hydrogen content in the examined samples of silver birch showed differences between average values of up to $0.62 \%$ (between Płońsk and Lipinki $\mathrm{FBF}$ ), while the difference between extreme values (maximum and minimum) reached $1.09 \%$ (between Sokołów and Lipinki FBF). The mean hydrogen content for all samples (6.39\%) was slightly higher than the figure previously reported in the literature $(6.06 \%)$ [31].

Minor differences, of up to $0.07 \%$, between average values of nitrogen content were recorded in the tested samples (between Bobolice FBF, FMBF and Łobez FBF, FMBF). The difference between extreme values (maximum and minimum) reached $0.10 \%$ (between Łobez FBF, FMBF and Górowo Iławieckie FBF, FMBF). The average content $(0.16 \%)$ reported in this study could not be compared due to the lack of corresponding data in other studies. Nitrogen is a chemical element that can be found in smaller amounts in the ligneous parts of plants. This results from their particular chemical composition, based on polysaccharides and lignin, in which nitrogen compounds are not found. During the oxidation of nitrogen to oxides (NOx) energy is released. The reaction of nitric oxides with water is an additional factor, resulting in nitric acids, in which nitrogen can be found in different oxidation states. These reactions also, to a lesser extent, affect the heat of combustion and the calorific value of wood.

The average chlorine content $(0.0064 \%)$ reported in this study could not be compared due to the lack of corresponding data in other studies. Chlorine is found in the tissues of arborescent plants, associated with alkaline elements such as sodium, potassium and sometimes calcium. The presence of chlorine in fuels is undesirable, because of the influence of compounds of this element on the thermal corrosion of energy installations. Additionally, chlorine reacts with aromatic compounds to form hazardous substances with carcinogenic properties.

It has been shown that under specific growth conditions, birch forms successive annual rings which, in terms of their elemental composition and fuel properties, generally differ to a small extent. The observed differences between locations and habitats may also result from diversified growth conditions influenced by various factors, including climate, soil and hydrology. However, we are not aware of any similar studies on this topic. On the other hand, the reasons for the occurrence or absence of differences between age groups are difficult to explain based on the collected observations. A few other studies $[14,15,17,18]$ have reported the influence of tree age on the fuel properties of wood, but none have suggested reasons. The causes of the observed differences may be explained in the future based on the analysis of wood morphogenesis. The results obtained here provide a premise for conducting research aimed at understanding the factors modifying the process of wood formation and the differentiation of its properties.

\section{Conclusions}

This work constitutes the result of a study of the fuel properties of silver birch (Betula pendula Roth.) wood - the widest such 
study thus far in Poland and one of only a few worldwide. Analysis of the findings concerning the heat of combustion, calorific value, ash content and elemental composition of the silver birch wood depending on location, tree age and forest habitat type allows the following conclusions to be stated:

- The location was shown to have a significant influence on the calorific value $(p=0.0001)$, ash content $(p<0.0001)$, carbon content $(p<0.0001)$, hydrogen content $(p<$ $0.0001)$, nitrogen content $(p<0.0001)$ and chlorine content $(p<0.0001)$.

- There are significant differences between values of ash content $(p=0.046)$ and calorific value $(p=0.0026)$ depending on the forest habitat type.

- Tree age was not found to have a significant influence on the calorific value of wood.

- The sulphur content in the tested samples was below the detectable level for the analytical method applied.

From a technical point of view, the observed differences in the fuel properties (in spite of the presence of statistically significant variation) are of no practical significance. The high hydrophilicity of wood dictates that moisture content is the main factor influencing the calorific value of the material. Changes in the water content in technical wood (from about $15 \%$ to about $70 \%$ ) cause the calorific value to fall for around $15-5 \mathrm{MJ} / \mathrm{kg}$. The assumption can be made that the calorific value of silver birch (Betula pendula Roth.) wood can be determined by averaging the collected data. The position is similar with respect to the other measured parameters (content of ash, carbon, hydrogen, nitrogen, sulphur and chlorine).

Funding Information This work was supported by the General Directorate of the State Forests in Poland [grant number EO-2717-13/13].

Open Access This article is distributed under the terms of the Creative Commons Attribution 4.0 International License (http:// creativecommons.org/licenses/by/4.0/), which permits unrestricted use, distribution, and reproduction in any medium, provided you give appropriate credit to the original author(s) and the source, provide a link to the Creative Commons license, and indicate if changes were made.

\section{References}

1. McKendry P (2002) Energy production from biomass (part 1): overview of biomass. Bioresour Technol 83:37-46

2. Ghugare SB, Tiwary S, Tambe SS (2014) Computational intelligence based models for prediction of elemental composition of solid biomass fuels from proximate analysis, Int J Syst Assur Eng Manag 1-14

3. Uzun H, Yildız Z, Goldfarb JL, Ceylan S (2017) Improved prediction of higher heating value of biomass using an artificial neural network model based on proximate analysis. Bioresour Technol 234:122-130
4. Obernberger I, Brunner T, Barnthaler G (2006) Chemical properties of solid biofuels - significance and impact. Biomass Bioenergy 30: 973-982

5. Jenkins BM, Baxter LL, Miles TR Jr, Miles TR (1998) Combustion properties of biomass. Fuel Process Technol 54:17-46

6. Liao CP, Wu C, Yanyongiie, Huang HT (2004) Chemical elemental characteristics of biomass fuels in China. Biomass Bioenergy 27: 119-130

7. Central Statistical Office of Poland, Forestry 2016, https://stat.gov. $\mathrm{pl} / \mathrm{en} /$ topics/agriculture-forestry/forestry/forestry-2016,1,7.html , Accessed 15 Nov 2017

8. Lachowicz H, Wysocka-Fijorek E, Paschalis-Jakubowicz P (2016) Silver birch timber market in Poland in 2008-2012. Sylwan 160(12):971-980

9. Lachowicz H (2011) Influence of location and age on the value of wood strength coefficients for silver birch (Betula pendula Roth.). Sylwan 155(8):535-545

10. Lachowicz H (2011) Effect of tree thickness on the selected structural and physico-mechanical properties of silver birch (Betula pendula Roth.) wood. Sylwan 155(9):581-588

11. Lachowicz H, Paschalis-Jakubowicz P (2011) Variability of the wood fibre structure indices for silver birch (Betula pendula Roth.) in north-eastern Poland. Sylwan 155(7):446-458

12. Lachowicz H, Paschalis-Jakubowicz P (2014) Impact of a fresh broadleaved forest site and fresh mixed broadleaved forest site on selected parameters and ratios of silver birch (Betula pendula Roth.) wood fibre structure. Drewno 57(193):109-117

13. Lachowicz H, Jednoralski G, Paschalis-Jakubowicz P (2014) Effect of habitat on the selected structural and physico-mechanical properties of silver birch (Betula pendula Roth.) wood. Sylwan 158(4):285-291

14. Montes CS, da Silva DA, Garcia RA, de Muniz GIB, Weber JC (2011) Calorific value of Prosopis africana and Balanites aegyptiaca wood: relationships with tree growth, wood density and rainfall gradients in the West African Sahel. Biomass Bioenergy 35:346-353

15. Santana WMS, Calegario N, Arantes MDC, Trugilho PF (2012) Effect of age and diameter class on the properties of wood from clonal eucalyptus. CERNE 18(1):1-8

16. Lemenih M, Bekele T (2004) Effect of age on calorific value and some mechanical properties of three Eucalyptus species grown in Ethiopia. Biomass Bioenergy 27:223-232

17. Kumar R, Pandey KK, Chandrashekar N, Mohan S (2010) Effect of tree-age on calorific value and other fuel properties of Eucalyptus hybryd. J For Res 21:514-516

18. Kumar R, Pandey KK, Chandrashekar N, Mohan S (2011) Study of age and height wise variability on calorific value and other fuel properties of Eucalyptus hybrid, Acacia auriculaeformis and Casuarina equisetifolia. Biomass Bioenergy 35:1339-1344

19. Forest Data Bank 2017, https://www.bdl.lasy.gov.pl/portal/t-en, Accessed 15 Nov 2017

20. Wolski J (1969) Pierśnica - reprezentatywną cechą do wyboru drzew próbnych przy oznaczaniu fizycznych i mechanicznych właściwości drewna. Sylwan 113(8):77-78

21. Grochowski J (1973) Dendrometria. PWRiL, Warsaw

22. EN 14775:2009 Solid biofuels - determination of ash content

23. EN 14774-3:2009 Solid biofuels - determination of moisture content — oven dry method - part 3: moisture in general analysis sample

24. EN 15104:2011 Solid biofuels. Determination of total content of carbon, hydrogen and nitrogen. Instrumental methods

25. EN 15289:2011 Solid biofuels. Determination of total content of sulfur and chlorine

26. EN 14918:2009 Solid biofuels. Determination of calorific value

27. Bruchwald A 1989 A. Statystyka matematyczna dla leśników. Wydawnictwo SGGW. Warszawa

28. Kala R (2009) Statystyka dla przyrodników. Wydawnictwo Uniwersytetu Przyrodniczego w Poznaniu, Poznan 
29. Obernberger I, Thek G (2010) The pellet handbook, The production and thermal utilisation of pellets, Earthscan from Routledge, New York - Oxon

30. van Loo S, Koppejan J (2010) The handbook of biomass combustion and co-firing, Earthscan publishing for sustainable future, London, Washington, DC

31. Galewski W, Korzeniowski A (1958) Atlas najważniejszych gatunków drewna. PWRiL, Warsaw

32. Prosiński S (1984) Chemia drewna. Państwowe Wydawnictwo Rolnicze i Leśne, Warsaw
33. Janezic TS, Danon G, Bujanovic B, Dedic A (1993) Correlation between chemical composition and heating value of some domestic wood species. Drevársky Výskum 38(3):1-7

34. White RH (1987) Effect of lignin content and extractives on the higher heating value of wood. Wood Fiber Sci 19(4):446-452

35. D. Fengel, G. Wegener, Wood, chemistry, ultrastructure, reactions, Walter de Gruyter \& Co., Berlin, New York, 1984

36. Rowell RM (2013) Handbook of wood chemistry and wood composites. CRC Press Taylor\&Francis Group, Boca Raton

37. EN ISO 17225-2:2014-07 Solid biofuels-fuel specifications and classes - part 2: graded wood pellets 